\title{
The Axiological Approach to the Analysis of the Problems of Modern University Education
}

\author{
Aida V. Kiryakova \\ Tatiana A. Olkhovaya \\ Orenburg State University, Orenburg, Russia \\ Email: t251589@mail.ru \\ Gennady A. Melekesov \\ Orsk Humanitarian Technological Institute (branch) of OSU, Orsk, Russia \\ Alexey A. Presnov
}

Orenburg branch of the Volga State University of Telecommunications and Informatics, Orenburg, Russia

\section{Doi:10.5901/mjss.2015.v6n2s3p22}

\begin{abstract}
The urgency of the problem under investigation is conditioned by the uncertainty of modern information society that demands from university education to focus not on acquiring "ready" knowledge in certain subjects, but on preparing the students for the perpetual new and unconventional objectives; on the students' awareness of their own educational activity; on designing and implementing their own educational route in line with the changing real-life and professional situations. The article seeks for determination of the essential characteristics of axiologization in modern university education as a process of implementation of axiological self-determination of teachers and students. The axiological approach for studying the problem has become a prevailing one. The article submits a classification of the university education values; the definition of the concepts of "axiological potential of a person", "axiological self-determination", "axiologization", "subjectivity"; describes the axiological component of the university corporate culture. The article submissions may be useful for the specialists in the field of university education, the researchers dealing with philosophy and sociology of education.
\end{abstract}

Keywords: axiology; axiological orientation; axiological self-determination; university education; subjectivity; corporate culture.

\section{Introduction}

\subsection{Thematic justification}

The situation of a personality's social growing-up in today's world is complex, contradictory, fluid. It is determined by the rapidly changing environment setting endless challenges to university education, creating new contexts, imposing new requirements and prospects. In the mainstream of emerging problems the need to pay more attention to the changes and personal transformations, to the issue of determining the dominant values of educational activities is becoming more evident.

In conditions of uncertain future we should pay attention to the growing significance of fostering the valueconscious personality traits, person's motivation and ability to self-determination through understanding the existential life forms including education. Against this background, the paper submits a new axiological understanding of the of university education, which determines the specification of its components and their relations by means of structuring axiological relationships in "teacher-student" interaction which leads to a positive change in their position in the educational and research activities.

The intensity of communication, expanding of the information field, efficiency of the rapid communications and new technologies do not only improve human resources, but also increase the risks in his activities. In particular terms of today we can observe the change in basic attitudes of an individual in the social and material world through improving such features as forecasting, freedom of choice, self-determination and heuristics. 
In this social context the issues that become particularly significant are the orientation of the individual in the surrounding world of objective values of the society and culture, in himself, in his possibilities; feeling confident in past and present events, in building the image of the future and his personal life prospect.

\subsection{The scientific problem}

The scientific problem is determined by the civilizational transformations occurring in the present, which require a reorientation of university education on the development of a new quality of a human capital, namely, motivation to learn throughout life, axiological self-determination, self-organization, the ability to find innovative solutions to the professional and real-life goals. The modern university has to determine the fundamentals to create conditions in which the creative potential of the studentship, their creative abilities are realized in solving the strategic objectives to achieve success in life.

Education is the main channel of introducing a future specialist into the cultural, educational and professional values. At each stage of the development of society the education system undergoes certain changes according to its needs, ideology, values. The dramatic changes in the international community has resulted in new priorities in the field of university education. The civilizational shift has challenged the problems of axiology (the science of values), they again argue the values origin and evolution, the hierarchy and domination within the value system. Changing education in a changing world has brought to understanding of the need of a new strategy of university education.

It should be emphasized that the methodological basis of this issue is based on the theory of values presented in the studies of Russian and foreign scientists (Kagan, 1997) (Vyzhletsov, 1996) (Zdravomyslov, 1986), (Stepin, 2011), (Beck, Cowan, 2005), (Inglehart, 1995), (Schwartz, 2010).

\subsection{The scientific importance of solving the problem}

At present, the illusion of the possibility to solve the problems of development of university education only through the expansion of the resource (primarily financial) base of its existing structural elements is a serious threat. The actual risk (both financial and technological, and social) - is to invest into the reproduction of unprogressive university education. The inability of the majority of Russian universities to quickly and effectively respond to the system challenges of the modern world is determined not only by the lack of funding, but also by the mismatch between the traditionally established educational practices, programs and technologies and current requirements of the society and production. The long-term study of the rapidly obsolescent professional competencies objectively reduces the competitiveness of the country's human capacity in transition to the cognitive society claiming for the new forms of intellectual activity organization, new qualities of intellect and new quality of human capital.

The original purpose of education is to develop the personality able to take an independent and constructive attitude towards the external environment. In this case, it is not about adapting to the existing diversity in the social and professional spheres of life, but about the development of personal position in the process of university education basing on the assigned values and certain contents. It is the axiological resource that determines the effectiveness of activities including innovative ones.

The novelty of the research is determined by the fact that its solution will allow to consider the process of university education at a new angle, design it as an innovative, value-deterministic, creatively-active and subject-oriented process that increases the competitive advantages of both the university and its graduates.

\subsection{The specific objectives to be solved by the project}

The specific objective of this research is to study the main provisions of axiological concept of the university education development. The appeal to axiology and innovation theory of the university education sets as methodological guidelines of educational practice: personal meanings of education reflecting the ascent to real- life and professional values; achievement motivation; axiological self-determination, competency, social responsibility, leadership, synergy, creativity and subjectivity.

\subsection{Attainability of the solution}

Attainability of the problem solution and the opportunity to achieve theoretically and practically significant results is determined by the selection of methodological framework. The selected methodological framework and tools allow to 
reveal the axiological relationships in the educational process to the uttermost, to identify the risks and prospects for basic lines of university development in the globalizing world.

\section{Methodological Framework}

\subsection{The essence of theaxiological approach as a methodological framework of studying the problems of university education}

The axiological approach as a methodological foundation for investigating the problems of university education allows to determine the structure and hierarchy of values, which not only guide the future professional activity of the student, but also shapes his relations with the world and people. Due to its value-orienting function, the educational process takes students into the sphere of philosophical understanding of social and educational reality.

There is the reason to distinguish between at least two organically related elements: the values which in the near or distant future should become the focus of education and formation in the process of education the "objective" and "subjective" values, the values of its development. Therefore, the university education is a fundamental scientific and practical framework for the formation of real understanding of the true and false values of life and activities expressing social, legal and moral norms of society.

The education values constituting the essence of pedagogical axiology act at each stage of its development as moral imperatives. But these values are not the laws of pedagogical activity - they are the basis of self-organization and self-development - the generalized representation of the desired and necessary things for social communities. The values of education cannot be appointed by the authoritarian way, they evolve with the changing social and cultural environment. The diversity of the communities' life, the differences in educational systems facilitate the formation of a number of pedagogical practices that relying on human values build the new educational systems in every sphere of educational space.

\subsection{The potential of the axiological approach in the study of modern university education issues}

The axiological approach has now acquired the status of an interdisciplinary approach to the study of the phenomena and facts of social nature. This approach, reflecting the realities of the diverse spheres of human life, the person's attitudes to the world, to people and to himself, establishes a specific application area, a specific system of relations. In line with this approach, we study the problem of axiological origin of life that is general for all the sciences studying the human.

In this context, the merits of the axiological approach include the fact that it allows to consider the following problems of modern practices of university education at a new angle:

- the issues of formation and development of the person's value system in educational activities;

- the values of self-determination of the student's personality in science, society, and culture;

- the study of the axiological component of the formation of the person's basic competency in the information society;

- $\quad$ the relationship between the tradition and innovation in higher education;

- the development of the axiological potential of the students' and teachers' personalities;

- overcoming the tendency of social stratification on such grounds as socio-cultural establishments as an image and lifestyle, social identity, social position, social status.

The axiological approach involves consideration of the educational activities based on the established relationship of the subjective and objective, the actual and potential, the necessary and accidental, the traditional and innovative.

\section{Results}

\subsection{The basic values of university education}

Building a strategy of the university education development in the modern world it is necessary to identify the fundamental values of university education. According to the results of theoretic study and diagnostic testing using the Delphi method we have identified the following groups of basic values of university education:

The academic values (institutional independence, fundamentality, academic freedom, academic solidarity (collectivity); promoting the innovation growth, professional competency and new paradigms of teaching and research, academic responsibility, unity of educational and research process; academic mobility; critical thinking; tutorial 
relationship between the educator and the student (joining scientific schools); interdisciplinary research; international cooperation of teachers; elitism of university education).

The value of personal growth and well-being (self-determination; self- fulfillment; individuality; subject-subject relationships; continuity of education; the conformance of the human to environment and situation; professional mobility, health, corporativity, competitive graduates).

The values of civil society (freedom, democracy, openness, social justice, tolerance, ethics, cultural diversity, social responsibility).

Organizational values (decision-making based on congruence of interests and opinions; freedom in research; the status hierarchy based on the principle of scientific authority; technification of educational activities; standardization of the education quality (educational programs), creation of material values and knowledge, university competitiveness, the availability of educational programs for foreign students, strategic partnership of university and businesses).

\subsection{The rationale for the concepts of "axiologization of education" and "development of the axiological potential of the student's personality"}

It is essential to appeal to the concept of axiologization - a leading contemporary trend in the development of university education in a rapidly changing world. Axiologization is a way to implement the axiological approach to education which has been accepted as the leading methodological approach in teaching. In this paper axiologization is considered in the following meanings:

- a component of humanization of university education since in theory and practice it determines the content and hierarchy of humanistic values of education, where a person as the main value is a systematizing element;

- a method, the object of which is the development of creatively-axiological personality traits but for which it is impossible to make an act of creation, independent personal activity to achieve top results, significant life goals, professional development;

- an optimum of educational environment fostering the development of the personal insight, building lofty needs, building axiological capacity, forming the academic maturity of a student;

- a cultural part of education as it provides the translation of cultural values and the dialogue of cultures, reveals the uniqueness of each culture taking into account that the system of values is the matrix of culture.

The student's professional life and the quality of his professional activity largely depend on the level of his axiological potential. The development of the student's axiological potential suggests qualitative changes in valueconscious attitude to educational activities, to himself, to the future professional activity.

The axiological paradigm of pedagogy is based on a new understanding of the educational process as the personality's raising to the values of culture and science on the basis of a universal philosophical dialectical law of lofty needs.

\subsection{The axiological self-determination of the university students}

The axiological self-determination of the students is of special importance in the axiological paradigm of university education. Axiological self-determination as a pedagogical phenomenon is a process of gaining the meaning, the goals and resources of their personal lives in educational time and space. It suggests a qualitative change in the individual's attitude to his own life by forming a holistic view over the world and understanding his place in it. The driving force of selfdetermination is the achievement motivation.

The criteria and indicators of axiological self-determination of a person in education are:

- a cognitive one (the knowledge about the world, themselves, time, objective and meaning of life);

- $\quad$ an emotive one(the value-related attitude to the future life, value orientations);

- a pragmatist one (a set of skills of goal setting, planning, design, selection, construction of a temporal perspective of life, projects development and implementation).

The university is a place of the coupling-development of the university and personal space-time continua, which represent the educational environment activated by the subject; the integrity evolving in time and space, where one can find the meanings, accept the values and set the goals for future activities. The concept of space-time continuum of university education, according to V.D. Povzun, allows to characterize the university not from the only informativeprocedural point, but also to emphasize the dynamics of its development in time and space and reveal its educational, scientific, industrial and social ties with the world (Povzun, 2011). The internal features of the continuum are determined 
by the university corporate culture, the goals, values and traditions of the university life as well as by the style of pedagogical thinking, ways of interaction between the teachers and students.

The axiological self-determination of the individual in university education takes place both through the training courses syllabi addressing the problems of a human being and through the educational technologies enabling the person to reflect on his own life in a time perspective. Mastering the algorithm of goal-setting in educational activity results in transferring the logic of setting and achieving the goals from educational life to personal.

\subsection{Subjectivity formation}

The next area of applying the axiological approach to the university education is represented by the research of the students' subjectivity. Subjectivity as a pedagogical phenomenon represents a holistic axiological characteristic of a personality that reveals itself in the practical efficiency, axiological self-organization behavior. The student's subjectivity is the basis of his demand and use of the scientific knowledge as a methodological and technological means to solve his own educational and professional goals. The driving force for subjectivity formation appears the axiological selfdetermination as a process of gaining the meanings, goals, resources of the university education by the student.

We regard the university educational space as a context of a student's life which, at first, determines the student's individual educational programme, and secondly, it encourages self-development and self-organization; third, promotes developing a temporary life perspective and can either extend the resources for subjectivity formation or limit them.

We describe the role of the axiological personality structures as a source and a mechanism of self-organization of personal and professional growth as the leading idea of subjectivity formation of the university students. This idea is backed with the necessity of understanding the values and meanings of the university education content. The meaning that the student has perceived specifies the direction for his educational and professional activities, determines decisionmaking both personally and socially relevant.

\subsection{The axiological component of the university corporate culture}

The scope of research of axiological foundations of higher education includes the study of the university corporate culture, the processes of integration of traditional and innovative research trends, the search for the optimal balance between the classic academic ethos and post-academic values. This process has its differences both in practice of modernizing particular universities, and at the level of national system of higher education, and the macroregional socially and market oriented traditions.

In the structure of corporate culture we identify the axiological component ( the value-based orientations) as systematically important: it sets the objectives (individual and collective) and chooses means of achieving them within the values. It is the axiological approach that allows to consider the corporate culture as "common identity" characterized by a common commitment of the staff to the values, ethical principles, objectives and mission of the institution providing the interaction of the values (and hence - the interests, attitudes, aspirations) of an individual and the team (groups, organizations, communities ). It was found that the essential characteristic of the axiological core of the university corporate culture is the focus on a human, as culture brings the humanistic values and meanings to the corporate activities, and distinguishing the "human dimension" of different objects they form the core of culture. The axiological function reflects the qualitative state of culture, promotes the production and retention of corporate values, thus affecting the attitudes and beliefs of the subjects of the educational community: the corporate values become personally meaningful or come into conflict. The structure of the axiological component of the university corporate culture includes the following groups of values: humanistic, professional, social.

\section{Discussions}

\subsection{The present state of the research on this issue, the main directions of research in the world science}

The axiology of education is a perspective research area allowing to find the resources for improving the quality of education. The axiological approach is a necessary component of:

- $\quad$ understanding of the sustainable social development (Vyzhletsov, 1996);

- $\quad$ studying the interaction between the knowledge and axiological consciousness of a person (Kagan, 1997; Rozov, 1992);

- studying the phenomenology of axiological attitudes of a person (Alexeeva, 1984; Bobneva, 1995; Lapin, 
2003; Sobkin, 1994);

- The basis for the formation of the new scientific thesaurus and new educational paradigm (Bezdukhov, 2008; Kiryakova, 2010, 2013; Krajewski, 2001);

The social mission of an innovative academic university has been described in the works of (Barber, 2013; Wolfson, 1999; Ladyzhets, 2003; Ogurtsova, 1993).

However, the change of an angle of pedagogical views concentrated in the axiological paradigm requires specific studies that can reveal the originality in shaping the image of the world, image of the future, self-image; particularities in forming the students' subjectivity; axiological laws of competence formation. The explanation of the marked phenomena distinguishes our research from other research projects.

\subsection{The axiological paradigm of university education}

The axiological paradigm of education is built on a special thesaurus: a value, axiological attitude, axiological orientations, axiological self-determination, axiological interaction between the teacher and the student, the dominant values of the education content, the axiological determinants of personality development, axiological resonance, communication as the values exchange, value-conscious choice, axiosphere of culture, axiological potential.

\section{Conclusion}

The changing education in a changing world leads to reframing of the methodological foundations of the human sciences including pedagogy. The traditional ideas about the laws of intellectual development, the formation of creative potential absorb new theories, concepts, innovative technologies, models, various educational programs and require greater attention to the fundamentals of science and practice. At present, one of the strategic guidelines for university education is the axiological paradigm of pedagogy. The axiology of education is a promising research area that can answer many questions, the solution of which can arrange for improving the quality of education. The main reserve for increasing the quality of education in the context of axiology appears the personal potential of the students and university teaching staff.

\section{Recommendations}

The article submissions may be useful for the specialists in the field of university education. The potential capacity of the results obtained in our research project lies in the ability to use the axiological resource to improve the quality of university education (through the development and implementation of the scientific and methodological support for the processes of the students' axiological self-determination, rexpress their subjective position, advanced training for teachers, developing the competitiveness of the university graduates).

\section{References}

Alekseeva, V.G. (1984) The axiological orientations as a factor of human activity and personal development. Philological Journal, 5, 6370.

Barber, M., \& Donnelly, K. (Eds.) (2013). An avalanche is coming. Higher education and the revolution ahead. London, The Institute for Public Policy Research.

Beck, D., Kovan, K. (2010). A spiral dynamics: managing values, leadership and change in the XXI century. Saint Petersburg, St. Petersburg, 132.

Bezdukhov, V.P., Zhirnova, T.V. (2008) The axiological sphere of the student's consciousness: a diagnostics and formation. Moscow, Moscow Psychology-Social Institution, 243.

Bobneva, M.I.(1995) The axiological priorities of an individual and the group. Moscow, 212.

Inglehart R.F., Abramson P. (1995) Value change in global perspective. Michigan, University of Michigan Press.

Kagan, M.S. (1997) The philosophical theory of value. St. Petersburg, Saint Petersburg.

Kiryakova A., Olkhovaja T., Mjasnikova T. (2013) Axiological Self-Determination of University Students in the Contemporary Media Landscape. Middle-East Journal of Scientific Research, 17 (2), 182-186, 1990-9233, DOI: 10.5829 / idosi.mejsr.2013.17.02. 12184.

Kiryakova, A.V., Olkhovaya, T.A. (2010) Axiology and Innovation of university education. Moscow.

Krajewski, V.V. (2001) The methodology of pedagogy. Cheboksary.

Ladyzhets, N.S. (2002) The philosophy and practice of university education. Izhevsk.

Lapin, N.I. (2003) The dynamics of the population values in the reformed Russia. Moscow.

Ogurtsov, A.P. (1993) Philosophy of science of the Enlightenment. Moscow. 
Povzun, V.D. (2011) The mission of the university as an axiological phenomenon. Electronic scientific journal "Axiology and education innovation", 2, http://www.orenport.ru/axiology/docs/19/17.pdf

Rozov, N.S. Culture, values and education development. Moscow.

Schwartz S.H. (2010) Values for Life: How Values Inspire and Motivate Decisions. Ballarat: University of Ballarat.

Sobkin, V.S., Pisarskiy, P.S. (1994) Life values and attitude toward education: cross-cultural analysis. Moscow, 332.

Stepin, V.S. (2011) Globalization and Dialogue of Cultures: the problem of values. Century of Globalization, 2, 8-17.

Vyzhletsov, G.P.(1996) Axiology of culture. Saint Petersburg, 114.

Wolfson, B.L. (1999). A strategy for the development of education in the West on the threshold of XXI century. Moscow.

Zdravomyslov, A.G. (1986) Requirements. Interests. Values. Moscow. 